Gut, 1972, 13, 211-219

\title{
Mass peristalsis in the human colon after contact with oxyphenisatin
}

\author{
JAMES RITCHIE \\ From the Nuffield Department of Clinical Medicine, the Radcliffe Infirmary, Oxford, and the Nuffield \\ Department of Medical Research, Oxford
}

SUMMARY Colonic motility studies using time-lapse cinefluorography and intraluminal pressure recording before and after the introduction per rectum of a mixture of barium sulphate and oxyphenisatin solution show the different forms of movement of the colonic contents.

Oxyphenisatin was found to be a selective actuator of a form of progressive mass propulsion indistinguishable from spontaneous mass peristalsis. Less than $0.5 \mathrm{mg}$ distributed through the pelvic and distal descending colon was enough to produce a peristaltic response; larger quantities tended to increase the number of resulting movements.

A standard dose of $4 \mathrm{mg}$ of the drug was followed by mass peristalsis in $82 \%$ of the subjects in whom it came into adequate contact with colonic mucosa. The response usually took place within 20 minutes. The more sensitive the subject, the greater was the number of peristaltic responses and the shorter the interval before the response began.

In $73 \%$ of the subjects who responded, the mass peristalsis came to a halt between 40 and $25 \mathrm{~cm}$ from the anal margin, and many of those in whom it extended farther appeared to have shortened distal colons. The likelihood of the drug giving rise to peristalsis diminished abruptly distal to about $45 \mathrm{~cm}$ from the anus; its effectiveness was greatest in the proximal descending colon.

Oxyphenisatin, the active aperient principle of prunes, has been shown to act as a contact laxative (Hardcastle, Mann, Parks, and Murray, 1967). This is a property which it shares with bisacodyl (Hardcastle and Mann, 1970) and rhein anthrone, a hydrolysed reduction product of senna (Hardcastle and Wilkins, 1970).

These substances appear to 'sensitize' the neurones of the submucous plexus in the colonic wall to stimuli such as distension which, in the small intestine, would of themselves give rise to a peristaltic reflex. The effect of contact laxatives can be blocked by lignocaine provided that this is applied before sufficient penetration of the drug has taken place (Hardcastle et al, 1967).

This study was undertaken to record the action of oxyphenisatin on the movement of colonic contents when introduced per rectum into the distal bowel in a wide range of clinical and functional conditions.

\footnotetext{
1Address for communications: The Nuffield Department of Clinical Medicine, the Radcliffe Infirmary, Oxford

Received for publication ?1 December 1971.
}

\section{Material and Methods}

Colonic motility studies have been carried out on 73 occasions, using a technique of combined time-lapse cinefluorography with a $32-\mathrm{cm}$ image intensifier and intraluminal pressure recording as previously described (Ritchie, 1968). The 57 subjects taking part came from the wards and Outpatients Department of the Radcliffe Infirmary, Oxford; they formed a mixed group which included patients suffering from diverticular disease, ulcerative colitis, and the irritable colon syndrome as well as some with simple constipation and a number of normal volunteers. Although many of the clinical subgroups were small, they showed no indication of any quantitative differences in the degree of their responsiveness to oxyphenisatin, and in this respect the whole group will be regarded as homogeneous. Nor was there any consistent correlation with differences in the age, sex, or bowel habit of the subjects.

Each subject drank $100 \mathrm{ml}$ of Micropaque barium sulphate suspension at bedtime, about 13 hours before the start of the study period. Sigmoidoscopy, 
usually to about $20 \mathrm{~cm}$, was carried out on their arrival in the motility study room and a standard bundle of polythene tubes was introduced through the instrument to monitor changes in the intraluminal pressure. The proximal $15 \mathrm{~cm}$ of each tube was soft and flexible to avoid the potential dangers either of blind intubation or of extended sigmoidoscopy. Each tube was provided with a radiopaque tip and these were positioned at $38,30,15,3.5$, and $1.5 \mathrm{~cm}$ from the anal margin. With these five tubes was included a sixth for introducing the oxyphenisatin solution at $38 \mathrm{~cm}$ and one connected to a $15 \mathrm{ml}$ balloon, located between that point and the next recording tip at $30 \mathrm{~cm}$, for distending or occluding the bowel.

At the start of the study period the balloon was inflated to $60 \mathrm{ml}$, or less if the patient found that painful. It was kept distended for a few minutes after 10-15 $\mathrm{ml}$ of Micropaque suspension was introduced proximal to it, to ensure that the whole of the pelvic colon and its contents were adequately visualised. As a result of their flexibility, in 18 instances it was found that the leading tube tips had, in the course of insertion, turned back toward the rectum. The balloon then lay proximal to the site of introduction of the barium, which was often held up for some time in the rectosigmoid region.

All subjects were observed under resting conditions over an average period of 40 minutes with time-lapse cinefluorography at 1 frame/min. In 47 of the studies the subjects were given the ordinary hospital canteen lunch and observed for a further period averaging one hour. During these two observation periods all spontaneous movements of opaque contents in the colon were recorded and classified under the general headings of systolic (haustral, multihaustral, and mass propulsion) and progressive (peristaltic ripples and mass peristalsis) as described by Ritchie, Truelove, Ardran, and Tuckey (1971).

The balloon was then reinflated and about $35 \mathrm{ml}$ of a mixture of Micropaque suspension and oxyphenisatin was introduced. In most instances the dose of oxyphenisatin was $4 \mathrm{mg}(6 \mathrm{ml}$ of PCL 243 solution (Damancy) containing $20 \mathrm{mg}$ in $30 \mathrm{ml}$ ), but the actual quantities of PCL 243 solution that were used varied between $0.5 \mathrm{ml}$ and $8 \mathrm{ml}$. Timelapse cinefluorography, usually at 3 frames/min, was maintained for a further period averaging about 38 minutes; during this time the movements of colonic contents that took place were classified in the same way as before. In 10 of the 18 studies in which the tubes had turned back, the oxyphenisatin failed to travel farther up the bowel within the limited duration of the study than about $45 \mathrm{~cm}$ from the anal margin.

\section{Definition}

The term 'mass peristalsis' is used here to identify a particular form of coordinated progressive propulsion occurring spontaneously in the colon. It begins with a general relaxation of segmental constrictions over a length of bowel, a change that forms the basis of all 'mass' propulsion and was first described in fluorographic terms by Holznecht in 1909.

De-segmentation is followed, after a variable interval, by the appearance of an annular constriction in the outline of the bowel with displacement of contents in both directions. The constriction extends only a short distance up the colon but may advance aborally for $100 \mathrm{~cm}$ or more at up to $30 \mathrm{~cm} / \mathrm{min}$, propelling bowel contents ahead of it. This is the characteristic progressive contraction of mass peristalsis and is made up of a combination of circular and longitudinal muscular activity. The contribution of the longitudinal muscle layer may be difficult to demonstrate in a study of this kind; its effect is usually limited to ensuring that friction between the bowel wall and an advancing mass of solid contents does not cause elongation of the bowel instead of effective propulsion. However, as the luminal resistance increases, the longitudinal component of the mass peristalsis assumes a more positive role in propulsion; in effect it pulls the bowel wall up over solid contents that are failing to advance ahead of the circular contraction and this process can sometimes be demonstrated by cinefluorography. Bayliss and Starling (1900), who fixed large balloons into the colons of dogs, described how redundant folds of the gut wall collected proximal to the obstruction, when repeated waves of peristalsis failed to move it.

Movement of the combined circular and longitudinal contraction along the bowel wall appears to be preceded over a variable distance by a descending wave of circular muscle inhibition. Like the longitudinal component of the propulsive contraction, pro-peristaltic inhibition probably amounts in most instances to no more than a minor change in the muscle's resistance to distension; as a result, it is difficult to distinguish with certainty on a pressure record from various forms of artefact, even when open-ended tubes are used to record it.

The chief differences between systolic mass propulsion and a mass peristalsis are illustrated in Fig. 1 with film from two separate patients. In the first two-minute series of prints a systolic propulsive movement partially empties the hepatic flexure and proximal transverse colon. The contraction occupies only a relatively short period of time and pushes the leading edge of the barium forward by narrowing and elongation; there is no recognizable advance of 


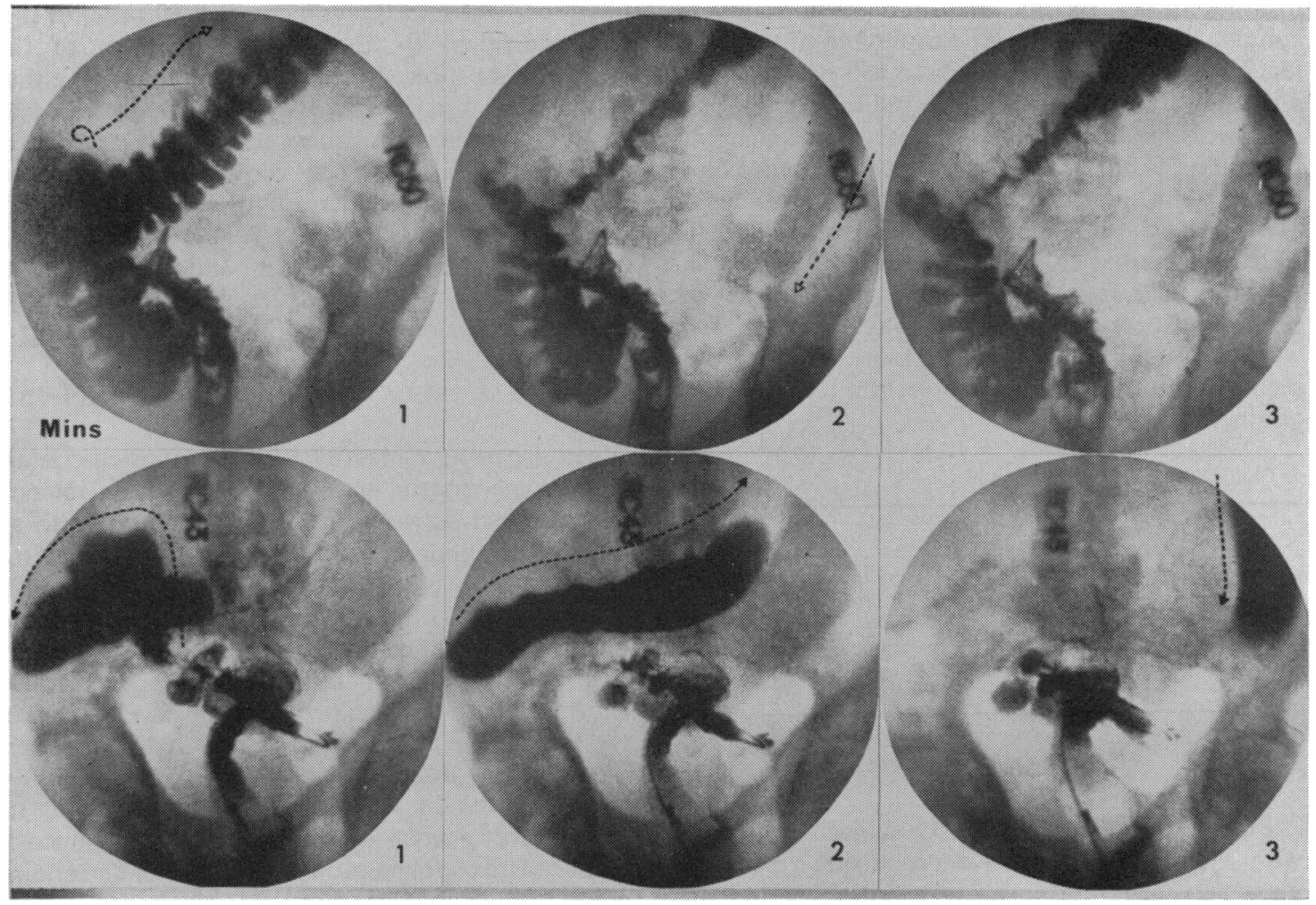

Fig. 1 Cinefluorographic prints at one-minute intervals taken from two separate patients to compare systolic and progressive forms of spontaneous mass propulsion.

Some time during the minute between the first two frames there is a contraction, chiefly involving the circular musculature of the bowel wall between the distal ascending and distal transverse colon. Emptying of this section of bowel is incomplete. There is nothing to indicate progression of the contractile process, which takes place within a relatively short period and advances the leading edge of the opaque contents by elongation. The mass of displaced contents in the descending colon is not segmented; its outline is relatively narrow and pointed, and shows no evidence of receptive relaxation of the bowel wall ahead of its advance.

The lower three frames illustrate part of a mass peristalsis covering the same length of bowel, in which segmentation has also been inhibited. Here the contraction itself advances as a progressive wave, which propels opaque bowel contents ahead of it in the form of a discrete mass and leaves the bowel empty behind it. The leading edge of the barium mass is bluntly rounded, or even slightly bulbous in the second frame, suggesting a coordinated diminution of the luminal resistance.

the constriction itself and the barium mass tends to assume a pointed outline as it overcomes the luminal resistance to its advance. The second three frames, again at one-minute intervals, show part of a mass peristaltic movement in which there is a steady aboral progression of the contractile process. This propels the whole barium mass ahead of it in isolation at a constant rate of about $30 \mathrm{~cm} / \mathrm{min}$, leaving the bowel empty behind it. The moving mass of barium is shorter than it was under resting conditions and its leading edge is rounded. This suggests that it is advancing through gut in which the luminal resistance has been diminished by descending inhibition.

\section{Results}

OXYPHENISATIN AND THE MOVEMENT OF COLONIC CONTENTS

Mass peristalsis occurred spontaneously under resting conditions in only three out of 73 observations over an average period of $\mathbf{4 0}$ minutes. This is equivalent to an hourly incidence of six peristaltic movements per hundred subjects studied. Mass peristalsis was also seen in two out of 47 one-hour postprandial studies, which is approximately the same rate of occurrence.

During 73 studies using the same group of subjects, varying doses of oxyphenisatin in Micropaque were 
introduced per rectum. In 10 of them, mucosal contact with oxyphenisatin was limited to $45 \mathrm{~cm}$ or less of the distal bowel and these will be considered separately. In the other 63 studies the bariumoxyphenisatin mixture travelled varying distances up the colon (Table I). In 12 it stopped in the proximal pelvic colon, somewhere between $45 \mathrm{~cm}$ and the line of the pelvic brim; in 22 it reached a point in the distal descending colon below the level of the iliac crest, and in 29 it passed beyond that into the proximal descending colon. In some instances there were delays of 20 minutes or more before it was seen to advance from one section of bowel to another.

\begin{tabular}{lllll}
\hline \multicolumn{4}{c}{ Barium Shadow Visible to: } \\
\cline { 2 - 5 } & $<45 \mathrm{~cm}$ & $\begin{array}{l}\text { Proximal } \\
\text { Pelvic } \\
\text { Colon }\end{array}$ & $\begin{array}{l}\text { Distal } \\
\text { Descending } \\
\text { Colon }\end{array}$ & $\begin{array}{l}\text { Proximal } \\
\text { Descending } \\
\text { Colon }\end{array}$ \\
\hline $\begin{array}{l}\text { Number of } \\
\text { subjects }\end{array}$ & 10 & 12 & 22 & 29 \\
\hline
\end{tabular}

Table I Proximal extent of oxyphenisatin distribution

Forty-nine $(78 \%)$ of the 63 subjects responded with a form of progressive propulsion resembling mass peristalsis during an observation period that averaged 37 minutes. Progressive mass propulsion did not occur among the other 14 subjects, who were observed for an average of 45 minutes from the introduction of the barium mixture.

In addition, the 47 subjects who were observed over an average period of 100 minutes under resting conditions and after eating lunch, and the 26 who were only observed at rest, developed between them 21 systolic propulsive movements and nine examples of systolic retropulsion. These figures may best be represented for comparison as a combined total hourly incidence of systolic movements per hundred subjects and, as Table II shows, for 73 subjects

\begin{tabular}{|c|c|c|c|}
\hline \multicolumn{2}{|c|}{ Movements Observed } & \multirow{2}{*}{$\begin{array}{l}\begin{array}{l}\text { Combined Hourly } \\
\text { Incidence at Rest } \\
\text { and after Lunch } \\
\text { (average } 80 \text { minutes) }\end{array} \\
\left.\begin{array}{c}22 \\
9 \cdot 5\}\end{array}\right\} 1.5\end{array}$} & \multirow{2}{*}{$\begin{array}{l}\begin{array}{l}\text { Estimated Incidence } \\
\text { after Oxyphenisatin } \\
\text { (average } 38 \text { minutes) }\end{array} \\
\left.\begin{array}{l}15 \\
25\end{array}\right\} 40\end{array}$} \\
\hline Systolic & $\begin{array}{l}\text { Propulsion } \\
\text { Retropulsion }\end{array}$ & & \\
\hline $\begin{array}{c}\text { Peristaltic } \\
\text { ripples }\end{array}$ & Propulsive & \}$_{15.5}$ & 10? \\
\hline $\begin{array}{l}\text { Progressiv } \\
\text { propulsi }\end{array}$ & $\begin{array}{l}\text { Retropulsive } \\
\text { mass } \\
\text { on }\end{array}$ & $\begin{array}{c}10 \cdot 5 \\
5\end{array}$ & $\begin{array}{l}17 \\
>78\end{array}$ \\
\hline
\end{tabular}

Table II Hourly incidence of different forms of colo nic propulsion per hundred observations observed over an average period of 80 minutes this was equivalent to about $31.5 \%$. Fifteen of the subjects also showed progressive movements, either propulsive or retropulsive, of the type described as peristaltic ripples, equivalent to an aggregate hourly incidence of $15.5 \%$. The combined incidence of systolic propulsion and retropulsion in 63 subjects whose colons had been in adequate contact with oxyphenisatin over an average period of 38 minutes was $40 \%$ per hour; that of peristaltic ripples in both directions after oxyphenisatin was $27 \%$.

SEGMENTAL RELAXATION AFTER OXYPHENISATIN

When progressive mass propulsion followed contact with oxyphenisatin, it took place after an interval which varied between one and 43 minutes, with an average of about 16 minutes. In every instance the propulsive movement was preceded by a substantial degree of relaxation of the segmental constrictions over the length of colon involved. The interval before this de-segmentation occurred was considerably shorter than that which preceded the development of the progressive contraction; it averaged about seven minutes.

Among the 14 subjects, in whom there was no progressive propulsion despite adequate mucosal contact with oxyphenisatin in the pelvic or descending colon, segmental relaxation occurred after an average interval of 13.5 minutes. This was a significantly slower response than that seen in subjects who experienced a mass peristalsis within the period of observations $(n=63, t=3 \cdot 7, P<0.01)$.

LONGITUDINAL CONTRACTION AFTER OXYPHENISATIN

In most of the 53 studies in which progressive mass propulsion occurred, the longitudinal component of the progressive contraction was not fluoroscopically distinguishable. This was probably because, in the absence of significant obstruction, the force exerted was no greater than that needed to keep the length of the colon approximately constant. Figure 2 shows an adoral movement of about $1 \mathrm{~cm}$ by diverticula lying over the pelvic brim as a small barium mass approaches them ahead of a peristaltic contraction wave. They are probably being pulled up by the longitudinal component of the peristaltic contraction, which would not have been discernible without the diverticular markers, and after the contraction wave has passed they return to their original position.

The longitudinal component of a mass propulsive contraction was capable of aboral progression along the gut in the same way as the contraction of the circular muscle layer. Figure 3, also taken from a patient with diverticular disease, shows a mass 


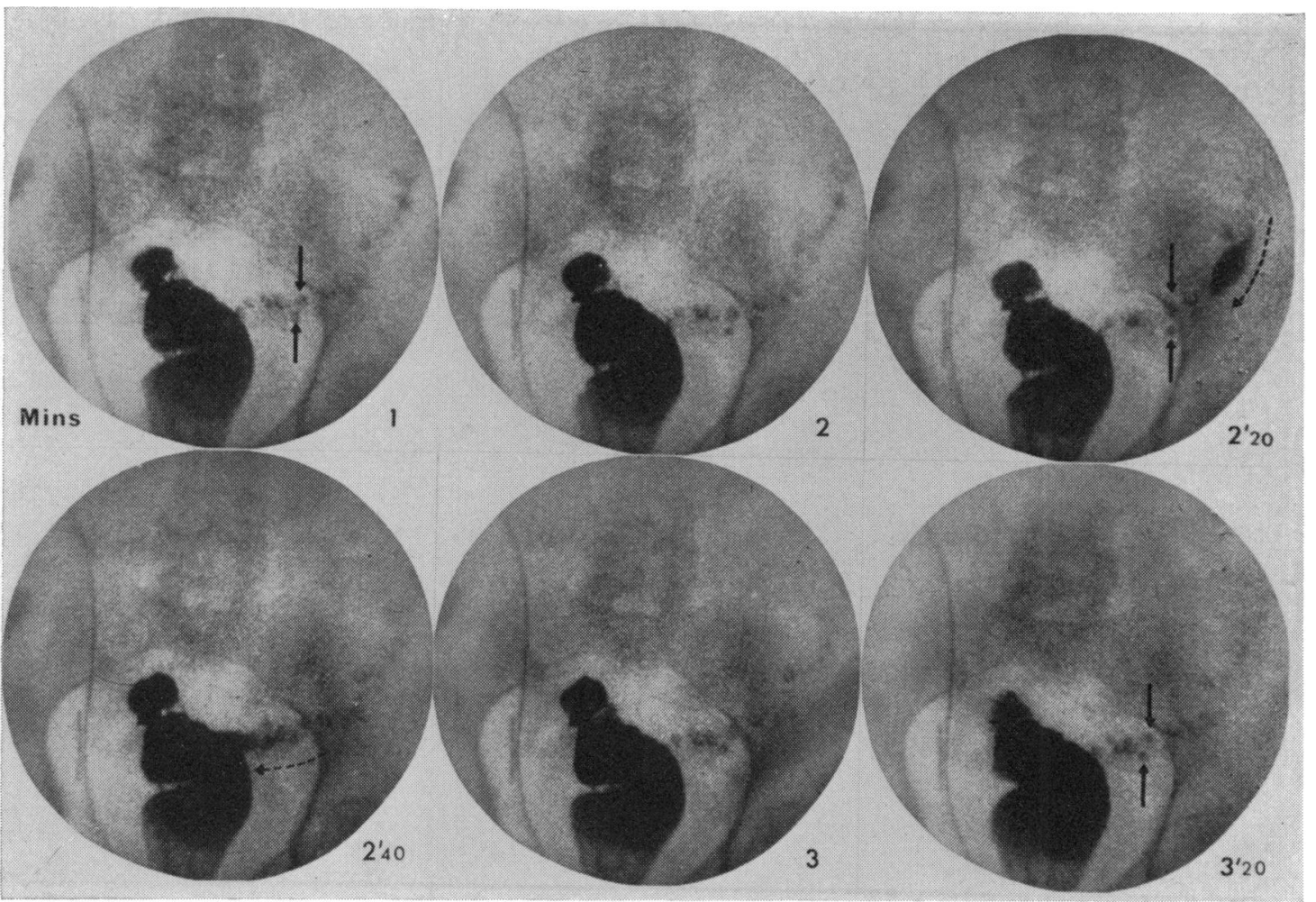

Fig. 2 The longitudinal component of progressive mass propulsion.

In this series of cinefluorograms from a patient with diverticular disease the time relations of each print are indicated by the figure accompanying it. A number of previous mass propulsive movements following mucosal contact with oxyphenisatin had emptied the descending and proximal pelvic colon and distended their diverticula. The position of the barium shadows outlining diverticula in the pelvic colon was constant under resting conditions until the approach in frame 3 of a further small mass of opaque bowel contents ahead of another propulsive wave. This was preceded by an adoral movement of about $1 \mathrm{~cm}$ by the two diverticula (arrowed) which were nearest to the pelvic brim. The diverticula remained in their new position for about half a minute after the circular contraction wave had passed over them and then, in the last frame of the series, they returned to their former site. Their movement was probably due to pull on the gut wall ahead of it by the longitudinal component of the progressive contraction.

peristalsis traversing the descending colon. Segmentation has been inhibited and by frame 2 a peristaltic constriction has reached the mid-descending colon. This is accompanied, and to some extent preceded, by longitudinal contraction of the bowel outline as shown by proximation of successive diverticular markers. In frame 3 the next more distal section of bowel contents adjacent to the pelvic brim has shortened in its turn and in frame 4 the outline of the proximal pelvic colon and the sigmoid loop has also contracted.

\section{DOSAGE OF OXYPHENISATIN}

Six subjects received $0.5-3 \mathrm{ml}$ of the oxyphenisatin solution, equivalent to $0 \cdot 33-2 \mathrm{mg}$ of the drug. Five of them showed progressive mass propulsion with an average of $2 \cdot 2$ such movements each in 31 minutes of observation (Table III). The time interval to the first movement averaged about 16 minutes.

\begin{tabular}{llll}
\hline $\begin{array}{l}\text { Dose of } \\
\text { Oxyphenisatin (mg) }\end{array}$ & $\begin{array}{l}\text { No. of Subjects } \\
\text { with Progressive } \\
\text { Mass Pro- } \\
\text { pulsion }\end{array}$ & $\begin{array}{l}\text { No. of Move- Individual } \\
\text { ments }\end{array}$ & \\
\hline & 5 verage \\
\hline $\begin{array}{l}0.33-2 \\
(0.5-3 \mathrm{ml} \mathrm{PCL} \mathrm{243)}\end{array}$ & 5 & 11 & $2 \cdot 2$ \\
$\begin{array}{l}2.6-4 \\
(4-6 \mathrm{ml} \text { PCL 243) }\end{array}$ & 46 & 180 & 3.9 \\
$\begin{array}{l}4.7-5.3 \\
(7-8 \mathrm{ml} \text { PCL 243) }\end{array}$ & 2 & 17 & 8.5 \\
\hline
\end{tabular}

Table III Average number of propulsive movements after different doses of oxyphenisatin 


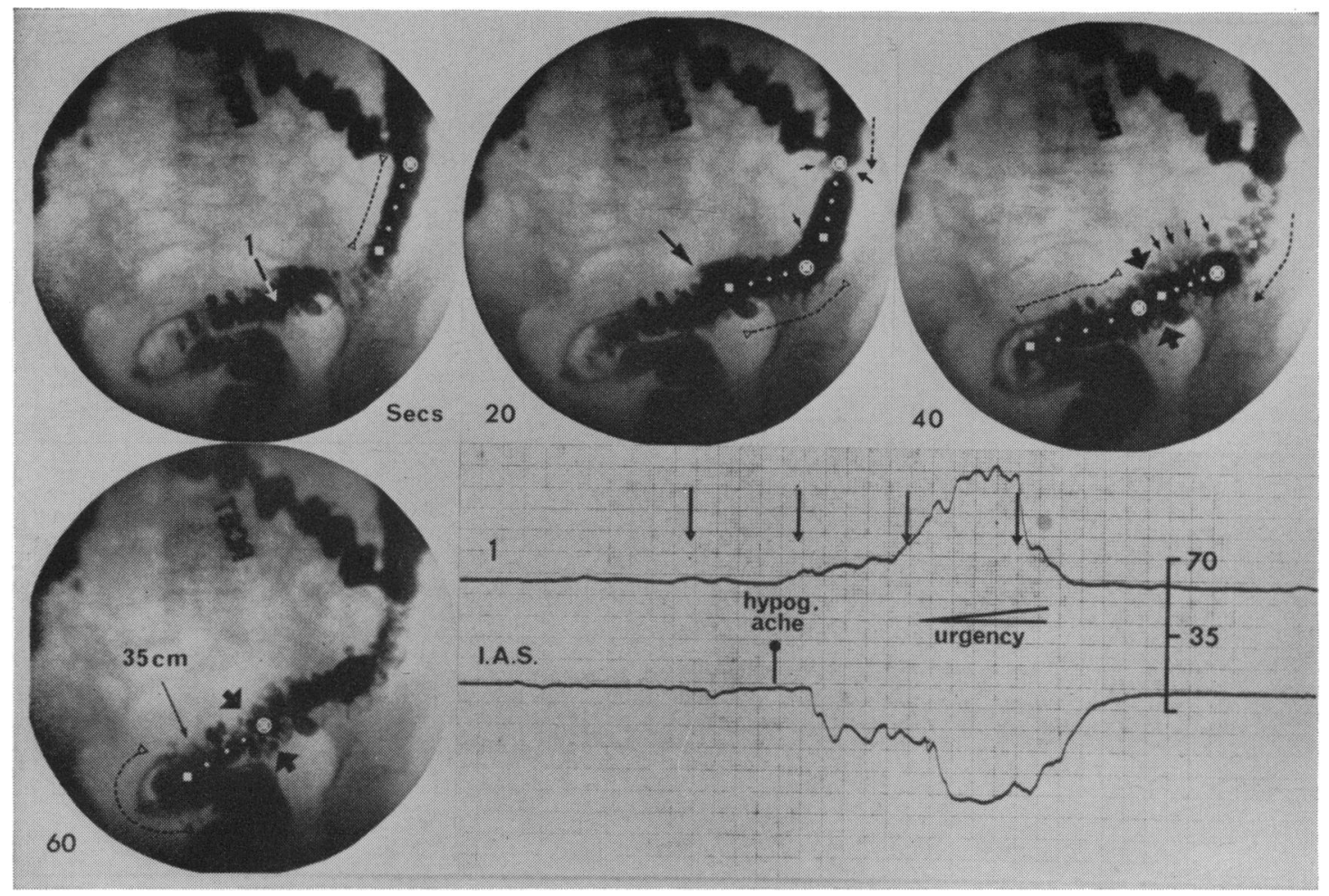

Fig. 3 Aboral progression of the longitudinal contraction.

These four frames of time-lapse cinefluorography, taken at 20-second intervals, illustrate progressive mass propulsion after oxyphenisatin in a patient with diverticular disease. The figure 1 in the first frame marks the position of the pressure recording tube-tip from which the upper pressure tracing is taken. The lower tracing is recorded from the level of the internal anal sphincter.

In the second frame the contraction ring of a progressive mass propulsion (medium sized arrow) has just come into view in the descending colon, which is distended with opaque contents as far ahead as tip 1. This provokes hypogastric griping and, five seconds later, partial relaxation of the internal anal sphincter. The section of bowel immediately ahead of the advancing constriction, marked out by diverticular (small arrows), is seen to shorten progressively over a period of 40 seconds as the constriction approaches and passes through it.

The next section marked out by diverticula, lying over the pelvic brim and extending down to the long arrow, shortens during the interval between frames 2 and 3, extruding a number of large diverticula. It is not clear what happens to the circular component of the progressive contraction in this section, but some degree of circular contraction appears to be displacing barium from the section of bowel between the broad arrows by frame 3. After this, pressure mounts steeply at tip 1 until contents can escape to the rectum, when anal sphincter relaxation becomes complete and there is an increasing urge to stool. Within two seconds the steep rise in the pressure record shows that tip 1 has become directly involved in contraction. The aboral progression continues over part at least of the last 20 seconds to frame 4; longitudinal contraction spreads into the distal pelvic colon, but there is no evidence of the circular contraction extending beyond about $35 \mathrm{~cm}$ from the anus.

In the other 67 studies the subjects were given 5-8 $\mathrm{ml}$ of oxyphenisatin solution and on $\mathbf{4 8}$ occasions they experienced a peristaltic-like reaction after a mean interval of approximately 15 minutes. In this group the response averaged $4 \cdot 1$ progressive movements in 38 minutes of observation. These figures do not in themselves represent a significant increase in bowel activity $(n=53, t=1 \cdot 54)$. However, when the 11 propulsive movements that occurred in five subjects given $3 \mathrm{ml}$ or less of oxyphenisatin solution are compared with 17 movements seen in two subjects who were given $7-8 \mathrm{ml}$, there is a highly significant difference $(n=7, t=6.2, P<0.01)$. The mean interval from mucosal contact to the first movement in these two subjects was 11 minutes, but this was not a significant reduction. 
LIMIT OF EFFECTIVE CONTACT WITH OXYPHENISATIN

In the 10 studies in which oxyphenisatin contact did not extend proximal to about $45 \mathrm{~cm}$ from the anal margin, only three of the subjects, with contact to 25,30 , and $45 \mathrm{~cm}$ respectively, responded with progressive mass propulsion. The progressive contractions were abnormal in that they extended down to $20 \mathrm{~cm}$ or less from the anal margin instead of terminating at the more usual endpoint at about 25 to $40 \mathrm{~cm}$ (Fig. 4). The first of the three subjects had severe diverticulitis and had also had an operation to fix the rectum after prolapse, and the other two had spastic constipation. As the pressurerecording tubes had turned back, the length of their distal colons could not be accurately assessed but two appeared to be somewhat shorter than usual. Distal extension of the progressive wave of contraction beyond $20 \mathrm{~cm}$ only occurred in seven subjects throughout the whole study; three of the other four had ulcerative proctitis and the fourth had a radiation stricture of the recto-sigmoid region. All of them had such a degree of functional or pathological shortening of the distal bowel that tip 1 at 38 $\mathrm{cm}$ was in the mid-descending colon. None of the seven subjects who did not respond with progressive mass propulsion after oxyphenisatin contact that was limited to $45 \mathrm{~cm}$ or less showed evidence of shortening.

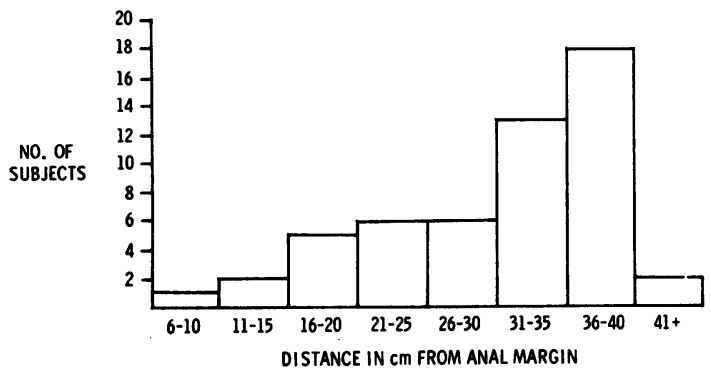

Fig. 4 Distal limit of progressive mass propulsion after oxyphenisatin.

Mucosal contact with the oxyphenisatin-barium mixture occurred in the distal bowel in all subjects, sometimes before it travelled farther up. However, only two subjects, in whom the drug later reached the descending colon, showed mass propulsion starting at or distal to $45 \mathrm{~cm}$. These were patients suffering from the irritable colon syndrome, whose pelvic colons were of normal length. From these figures, the likelihood of a propulsive movement starting in the terminal $45 \mathrm{~cm}$ of the bowel in response to this form of stimulation is only about one in 15 contacts or $7 \%$ (Table IV).

\begin{tabular}{lll}
\hline & \multicolumn{2}{l}{ Mucosal Contact with Oxyphenisatin } \\
\cline { 2 - 3 } & Distal to $45 \mathrm{~cm}$ & Proximal to $45 \mathrm{~cm}$ \\
\hline $\begin{array}{l}\text { Number observed } \\
\text { Number showing mass } \\
\text { propulsion starting }\end{array}$ & $5(7 \%)$ & 63 \\
\hline
\end{tabular}

Table IV Diminished response to oxyphenisatin within $45 \mathrm{~cm}$ of anus

INDIVIDUAL SENSITIVITY TO OXYPHENISATIN It is evident that any contacts of oxyphenisatin with the colonic mucosa which are inadequate in terms either of extent or duration can upset the results. In order to standardize as far as possible the conditions of the study, further assessment of the colonic response to oxyphenisatin was limited to 50 subjects who had all received $4 \mathrm{mg}$ of the drug. This had remained in contact with colonic mucosa proximal to $45 \mathrm{~cm}$ from the anal margin for at least 20 minutes, apart from a few who had already had a propulsive response within that period.

Forty-one ( $82 \%$ ) of these subjects responded with progressive mass propulsion. There were wide variations among them in the number of responses that occurred (Fig. 5), which appeared to form two peaks, one among relatively insensitive subjects and the other at a point representing three to four propulsive movements per subject. The time needed to develop a response also varied and Table $\mathrm{V}$ shows that the two parameters were directly related. Among the 14 subjects with only one or two progressive movements after oxyphenisatin, the average interval before the first was 22 minutes. At the other end of the scale, seven subjects responded with seven or more propulsive movements in succession, and in this group the average interval was only 11 minutes.

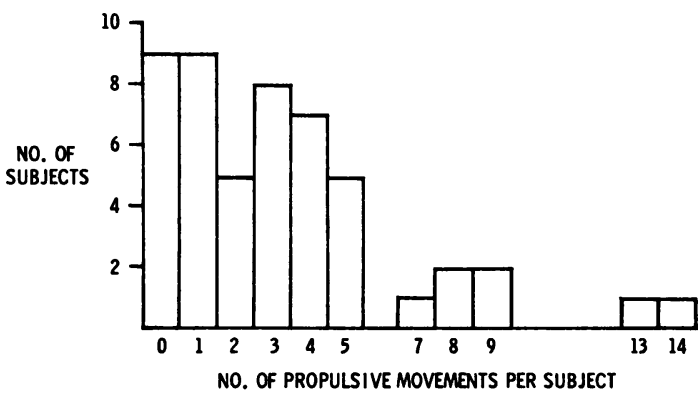

Fig. 5 Frequency of mass propulsive movements in response to $4 \mathrm{mg}$ of oxyphenisatin. 


\begin{tabular}{lllll}
$\begin{array}{l}\text { No. of propulsive } \\
\text { movements per subject }\end{array}$ & 0 & $1-2$ & $3-6$ & $7-14$ \\
$\begin{array}{l}\text { No. of subjects } \\
\text { Mean time interval } \\
\text { from contact to first } \\
\text { movement (min) }\end{array}$ & 9 & 14 & 20 & 7 \\
\hline
\end{tabular}

Table $\mathrm{V}$ Number of mass propulsive movements after $4 \mathrm{mg}$ of oxyphenisatin related to the mean interval before the first

Statistical comparison of the figures for these two groups shows that there is a highly significant difference between them $(\mathrm{n}=21, \mathrm{t}=3.4, \mathrm{P}<0.01)$. This was not due simply to limiting the duration of the first set of observations, as the average period of study for this group was $\mathbf{4 2}$ minutes after introducing the oxyphenisatin and that for the group with seven or more movements was 39 minutes.

\section{LOCAL SENSITIVITY TO OXYPHENISATIN}

Progressive mass propulsion was seen to start in the proximal pelvic colon in $20(40 \%)$ of the 50 subjects in whom there was oxyphenisatin contact in that section (Table VI). Further propulsive responses starting in the distal descending colon were seen in $20(49 \%)$ of the 41 subjects with mucosal contact there and in the proximal descending colon in 17 $(71 \%)$ of the 24 subjects. Statistical analysis shows that this is a significant progression $\left(\mathrm{n}=2, \chi^{2}=6 \cdot 2\right.$, $P<0.05)$.

\begin{tabular}{|c|c|c|c|}
\hline & \multicolumn{3}{|c|}{ Response to Oxyphenisatin in: } \\
\hline & $\begin{array}{l}\text { Proximal } \\
\text { Pelvic Colon }\end{array}$ & $\begin{array}{l}\text { Distal } \\
\text { Descending } \\
\text { Colon }\end{array}$ & $\begin{array}{l}\text { Proximal } \\
\text { Descending } \\
\text { Colon }\end{array}$ \\
\hline \multirow{4}{*}{$\begin{array}{l}\text { No. of contacts } \\
\text { No. showing } \\
\text { propulsion } \\
\text { Mean interval to } \\
\text { propulsion (min) } \\
\text { A verage no. of } \\
\text { propulsive } \\
\text { movements }\end{array}$} & 50 & 41 & 24 \\
\hline & $20(40 \%)$ & $20(49 \%)$ & $17(71 \%)^{1}$ \\
\hline & 17 & 19 & $12^{2}$ \\
\hline & 3 & 4.4 & $4 \cdot 7^{8}$ \\
\hline
\end{tabular}

Table VI Propulsive response to oxyphenisatin in different sections of colon

${ }^{1}$ Significant progression: $\mathrm{n}=2, x^{2}=6.2, \mathrm{P}<0.05$

'Significantly diminished: $\mathrm{n}=37, \mathrm{t}=2.3, \mathrm{P}<0.05$

so significant difference

The average number of propulsive movements that occurred in response to oxyphenisatin contact limited to the proximal pelvic colon was three; the corresponding figure for the distal descending colon was 4.4 propulsive movements and that for the proximal descending colon was $4 \cdot 7$. Neither of these represents a significant increase.

The mean interval before all responses starting in the proximal pelvic colon was 17 minutes, measured from the time the drug reached the actual starting point of each propulsive movement, and for those starting in the distal descending colon it was 19 minutes. This was not a significant difference, but the mean interval from mucosal contact in the proximal descending colon was down to 12 minutes which represents a significant reduction $(t=2 \cdot 3$, $P<0.05)$ compared with either of the other two sections of bowel.

\section{Discussion}

The chief problem in the identification of propulsive movements by time-lapse cinefluorography at 1 frame/min is to distinguish between an isolated systolic multihaustral contraction, strong enough to empty a section of bowel, and a mass peristalsis less than $30 \mathrm{~cm}$ long. Only on one occasion in the present series was there doubt about a contraction classified as systolic; if this had in fact been peristaltic it would only have altered the incidence of spontaneous movements in Table II from 5 to $6 \%$. Spontaneous mass peristalsis in the present series usually travelled farther than $30 \mathrm{~cm}$ and often only at 10 to $15 \mathrm{~cm} / \mathrm{min}$ so that the progression was apparent over three or more frames of cine even at 1 frame/min. One mass peristalsis involving apparently firm bowel contents covered only $20 \mathrm{~cm}$, but as it advanced at less than $15 \mathrm{~cm} / \mathrm{min}$ it was readily identified. Three mass peristaltic movements following oxyphenisatin were filmed at $1 \mathrm{fr} / \mathrm{min}$ and all travelled more than $30 \mathrm{~cm}$; there were also a number of actuated peristaltic movements between 15 and $30 \mathrm{~cm}$ in length, but these were filmed at 3 frames $/ \mathrm{min}$.

There seems little doubt that oxyphenisatin is a selective actuator of progressive mass propulsion with little or no effect on other forms of colonic propulsive activity. The increased incidence of systolic retropulsion and of retroperistaltic ripples was almost certainly caused by distension of the distal bowel with extra liquid contents. If the slightly increased incidence of propulsion by aboral peristaltic ripples after oxyphenisatin had any pharmacological significance it would suggest that the action of the drug is in some way to coordinate progression of the contractile impulse. This hypothesis is supported by the progression of longitudinal contractility, where that is recognizable, even when the circular component of the propulsive movement is weak or absent.

The combination of relaxation of segmental constrictions, progressive circular contraction, and sufficient longitudinal activity at least to keep the bowel length constant, represents the triad of muscular activity characteristic of mass peristalsis. 
This makes it highly probable that the colon's normal response to oxyphenisatin is a true mass peristalsis. It was not possible in any subject in the present series to demonstrate in numerical terms descending inhibition of the circular musculature ahead of a mass peristaltic wave. However, it is equally difficult to demonstrate this in spontaneous propulsion. Falls in the pressure of activity occurred about seven minutes after contact with oxyphenisatin in some tense and hypersegmented colons but these were probably due to other causes; the most likely was pro-peristaltic relaxation of the segmental constrictions, without which high pressures cannot be built up locally in the bowel. De-segmentation was seen to occur after the same mean interval from contact with the drug.

The abrupt fall in the prevalence of mass peristalsis as a response to oxyphenisatin distal to a point about $45 \mathrm{~cm}$ from the anal margin is probably related to the observation that three-fifths of all peristaltic movements starting below the splenic flexure came to an end at about 20 to $40 \mathrm{~cm}$. Variations in the longitudinal contractility of the distal bowel make accurate measurements impossible; however, there appears to be a fairly sharp transition zone in that region, beyond which at least the circular musculature of the colon is unlikely to show mass peristalsis. This observation is in conflict with those of Hardcastle and his coworkers that mass peristalsis usually reached the rectosigmoid junction. One possible explanation may lie in their use of subjects with defunctioning colostomies, in whom the distal bowel tends to be of small diameter and relatively shortened. In their studies of actuated mass peristalsis in the normal colon, Torsoli, Ramorino, Ammaturo, Capurso, Archangeli, and Pauluzi (1969) also found this form of propulsion absent from the rectum but it is not clear how precisely they delineated the distal limit of its advance. These workers were also unable to demonstrate a fall of intraluminal pressure ahead of a peristaltic contraction. However, they point out that when they used rubber tubing to form a model gut, there was an increase of pressure within it as its contents were propelled past their recording balloons; they argue that the elimination of this pressure rise in vivo is itself evidence of some 'receptive relaxation' of the bowel's normal resistance to stretch.

There appear to be three possible reasons why there should have been an increase in the peristaltic response as oxyphenisatin made contact farther up in the descending colon. One of them is based on the assumption that the combination of an increased peristaltic response and an increased capacity for systolic retropulsion in any bowel is due to a generalized hyperactivity. This is unlikely to be the explanation, because colons which showed retropulsion of barium and oxyphenisatin to the proximal descending colon did not make any more systolic propulsive movements than other colons. Another possibility is that the more neurones of the submucous plexus that come into contact with the drug, even in high dilution, the greater is the likelihood of starting a propulsive movement. The third possible explanation is that the proximal bowel is intrinsically more sensitive to oxyphenisatin than the distal bowel, either because of its better absorption or because the neuronal elements there are more sensitive to the drug. Further investigations will be needed to show which of these explanations is correct.

\section{References}

Bayliss, W. M., and Starling, E. H. (1900). The movements and the innervation of the large intestine. J. Physiol. (Lond.), 26, 107-118.

Hardcastle, J. D., and Mann, C. V. (1970). Physical factors in the stimulation of colonic peristalsis. Gut, 11, 41-46.

Hardcastle, J. D., Mann, C. V., Parks, A. G., and Murray, R. S. (1967). A study of colonic peristalsis. (Abstr.) Gut, 8, 633 .

Hardcastle, J. D., and Wilkins, J. L. (1970). The mechanism by which senna glycosides and related compounds stimulate peristalsis in the human colon. In Report of World Congress of Gastroenterology, Copenhagen, $\mathrm{p}$. 560.

Holznecht, G. (1909). Die normale Peristaltik des Kolon. Münch. med. Wschr., 56, 2401-2403. (Abridged translation (1969) Amer. J. dig. Dis., 14, 57-60).

Ritchie, J. A. (1968). Colonic motor activity and bowel function. I. Normal movement of contents. Gut, 9, 442-456.

Ritchie, J. A., Truelove, S. C., Ardran, G. M., and Tuckey, M. S. (1971). Propulsion and retropulsion of normal colonic contents. Amer. J. dig. Dis., 16, 697-704.

Torsoli, A., Ramorino, M. L., Ammaturo, M. V., Capurso, L., Archangeli, G., and Pauluzi, P. (1969). Mass movements and intracolonic pressures. Rendic. $R$. R. Gastroent., 1, 150-152.

\section{Addendum}

The observations of Reynolds and his coworkers since 1969 (Gastroenterology 1969, 56, 418; J. Amer. med. Ass., 1970, 211, 86; New Engl. J. Med., $1971,285,813$ ) have shown that oxyphenisatin ingested in a daily dosage of $6 \mathrm{mg}$ for at least 12 months may give rise to hepatitis. This appears to be a specific hypersensitivity reaction occurring in a few patients; challenge with the drug does not exacerbate hepatitis due to other causes. While this reaction makes its use as a regular oral aperient undesirable, oxyphenisatin remains at least as safe as the potassium soaps for occasional administration as an enema. A dose of 10-15 mg administered in this way, by actuating mass peristalsis, enables impacted scybala to be expelled even from the proximal part of the bowel efficiently and without discomfort. 